\title{
Eficácia na contratualização intergovernamental na Austrália
}

\author{
Evelyn Levy ${ }^{1}$
}

${ }^{1}$ Doutora em Administração.

Docente em Gestão de Políticas Públicas da Escola de Artes Ciências e Humanidades (EACH-USP) até 2007. Consultora em Gestão Pública.

Correspondência:

evelyn.levy@uol.com.br

\begin{abstract}
Resumo Esse artigo traz os resultados da pesquisa documental e das entrevistas feitas sobre os arranjos institucionais usados pelo governo australiano para facilitar a coordenação de atividades governamentais no governo federal da Austrália (Commonwealth) e os estados e territórios. O artigo conclui apresentando algumas considerações sobre a eficácia que o sistema tem demonstrado, assim como alguns de seus entraves e discute a possibilidade da adoção de algumas de suas inovações no federalismo brasileiro.
\end{abstract}

Palavras-chave: gestão de políticas públicas, governo federal, eficácia, federalismo, inovação.

Abstract This article presents the results of documental research and interviews about institutional arrangements in use by the Australian government to facilitate the coordination of governmental activities involving federal government of Australia (Commonwealth), the states and territories. The paper concludes presenting some considerations about demonstrated efficacy of the system, thus some of its barriers and discuss the possibility of adoption some of their innovations in Brazilian federalism.

Keywords: public policies management, federal government, efficacy, federalism, innovation. 
Resumen

El artículo presenta los resultados de pesquisas documentales y entrevistas conducidas sobre el formato institucional del gobierno australiano para facilitar la coordinación de las actividades del gobierno en el nivel federal de Australia (Commonwealth), los estados y territorios. El artículo concluye presentando algunas consideraciones sobre la eficiencia mostrada por el sistema, así como sus barrieras y discute la posibilidad de adopción de algunas de sus innovaciones en el federalismo brasileño.

Palabras-clave: gestión de políticas públicas, gobierno federal, eficacia, federalismo, innovaciones. 


\section{Mecanismos de coordenação intra e intergovernamental}

Em seu estudo intitulado Mind the gaps: managing mutual dependence in relations among levels of government (Charbit and Michalun 2009), a OCDE aponta para o fato de que os governos cada vez mais tendem a exercer suas atividades através de mais de um nível de governo, ou através de várias agências setoriais e/ou em parceria com o setor privado e os cidadãos. Isso acaba demandando a criação de mecanismos de coordenação vertical (para o primeiro caso), horizontal (para o segundo) e a criação de redes (no terceiro caso).

Da efetividade desses mecanismos depende a efetividade da ação governamental em várias áreas, bem como a eficiência do setor público como um todo. O estudo também assinala que vários são os mecanismos que vem sendo utilizados com esse objetivo: mecanismos legais, contratos, mecanismos de quase-integração, organismos de coordenação e mensuração de desempenho.

A Austrália vem construindo, especialmente nas últimas duas décadas, uma arquitetura organizacional que tem a finalidade de promover a coordenação entre a commonwealth, os estados e territórios, os governos locais e eventuais outros stakeholders (Carroll 2007). No centro desse arranjo está o Council of Australian Governments (COAG). Conforme Griffith (2009), na Austrália, hoje, todos os assuntos estratégicos no campo social, econômico e/ou ambiental, passam hoje pelo GOAG.

Entretanto, não é possível compreender essa arquitetura sem conhecer as múltiplas tensões que se desenvolvem nas relações federativas da Austrália. Ou seja, a eventual eficácia desses mecanismos não pode ser avaliada sem se considerar os estímulos e obstáculos que se interpõem entre os diferentes atores, causados pelo quadro legal que rege suas relações, sua realidade econômica e política.

\section{As relações federativas na Austrália}

A Commonwealth foi criada em 1901, a partir das colônias que então passaram a constituir os seis estados e dois territórios. Os fundadores da Commonwealth - o governo nacional da Austrália - tinham por objetivo abolir alfândegas criando um mercado único e fortalecer a defesa do país como um todo. Queriam, entretanto, manter o poder com os estados.

A constituição australiana prevê funções para o governo nacional e determina que todas as funções não expressas sejam entendidas como de responsabilidade dos estados. Em vários aspectos o governo nacional tem funções concorrentes com os estaduais. Ao longo do século XX, no entanto, os estados foram enfraquecendo, em geral, pelas seguintes razões (Griffith 2006): 
- Acontecimentos internacionais - como as guerras - criaram condições favoráveis à centralização, inclusive financeira;

- O crescimento de despesas nacionais - como defesa, infraestrutura e bemestar - fortaleceram o governo nacional;

- A Suprema Corte foi paulatinamente favorecendo a instância nacional como espaço de resolução de disputas;

- Os próprios partidos políticos, ao ocuparem o governo nacional, tendem a fortalecê-lo em detrimento dos estados.

A expressão mais óbvia desse enfraquecimento reside nos desequilíbrios financeiros existentes entre as duas instâncias. Em 1909-10, os governos estaduais e locais arrecadavam $78 \%$ dos impostos e taxas, enquanto a Commonwealth arrecadava $22 \%$. Atualmente $80 \%$ das receitas são arrecadadas pelo governo central, $17 \%$ pelos estados e $3 \%$ pelos governos locais, o que faz do sistema federativo australiano o de maior desequilíbrio vertical no mundo (RP).

As primeiras evidências desse desequilíbrio surgiram a partir de 1910, momento em que o governo nacional passou a fazer transferências aos estados para que pudessem arcar com os custos dos serviços que deveriam oferecer. Nesse primeiro estágio as transferências não eram vinculadas.

Em 1928 é criado o Loan Council, cujo objetivo era o de avaliar e autorizar centralizadamente os empréstimos internacionais contraídos pelos estados e territórios, dado que a dívida dos estados tinha se tornado insustentável (RP).

Em 1933 é criada mais uma instituição cujo propósito é o de promover a equalização fiscal horizontal. A Commonwealth Grants commission (CGC) tem, até hoje, a missão de sugerir ao Primeiro Ministro os percentuais em que deve ser repartido o volume total de transferências a serem feitas para os estados, de sorte a garantir que todo cidadão australiano tenha acesso a serviços equivalentes em qualquer ponto do território nacional.

A Commonwealth Grants Commission utiliza uma série de critérios - tamanho e perfil etário da população, localização urbana/rural, transferências diretas realizadas por setor, potencialidade de arrecadação dos estados (os estados podem recolher os seguintes impostos: sobre imóveis (exceto habitações), sobre folha de salários, sobre veículos motorizados, sobre seguros, sobre jogos de azar) - para fazer sua proposta.

A Commonwealth Grants Commission também calcula um valor médio para a produção de cada serviço e o ajusta conforme as variáveis citadas, atribuindoIhes um peso maior ou menor conforme as circunstâncias de cada estado. 0 objetivo maior é o de remover as diferenças financeiras entre os estados.

Ainda que a proposta de distribuição dos recursos não seja rigorosamente acatada, a criação da Commonwealth Grants Commission permitiu, desde aquele 
momento, que o governo nacional fizesse um acompanhamento estreito das finanças estaduais.

Durante a II Guerra Mundial, os estados concordaram em ceder temporariamente a parcela de arrecadação de imposto sobre a renda que realizavam. Ao final da guerra, no entanto, o governo nacional não retornou à situação do pré-guerra, passando a arrecadar sozinho todo o imposto sobre a renda, tornando a concentração fiscal ainda maior. Passa então a realizar transferências para os estados para que esses possam prestar serviços de educação, transportes, saúde, segurança, etc. (RP).

A Constituição atribui aos estados a responsabilidade primeira pela educação, treinamento, saúde, habitação pública, rodovias e outras infraestruturas de transporte e segurança pública, mas, ao longo dos anos 70, o governo da commonwealth começa a desempenhar um papel nas áreas da educação, água e da saúde. A elevação das expectativas dos cidadãos faz com que o governo nacional passe a interferir em áreas onde os estados se mostram pouco efetivos $(\mathrm{RP})$.

\section{O final dos anos 80, o new federalism de Hawke e a criação do COAG}

Nos anos 80, a Austrália se viu em meio a uma crise econômica severa. Tornouse evidente que sua participação, na economia mundial, dependeria de mudanças macro e microeconômicas. O dólar australiano desvalorizava-se cada vez mais, o que se tornou insustentável.

Keating, então ministro das Finanças do governo Hawke, chegou a advertir que a Austrália estava se tornando uma "república de bananas". No início dos anos 80, tiveram início as reformas macroeconômicas, como a abertura comercial e suspensão de barreiras tarifárias, a flutuação da moeda e a desregulamentação do sistema financeiro. Essas ações acabaram por devolver saúde fiscal à Austrália (RP).

Restava ainda serem realizadas as reformas microeconômicas, tal como propugnava a burocracia australiana adepta do "racionalismo econômico" e a OCDE (Carroll 2007). Entre elas destacava-se a necessidade de promover uma racionalização da regulação, inclusive a compatibilização das diferentes regulamentações existentes nos estados e territórios.

Era também preciso progredir nas questões referentes aos serviços de utilidade pública. Nesse momento uma parcela importante desses serviços era ainda produzida por monopólios estatais, pertencentes aos governos estaduais. Portanto era preciso envolver os estados nos processos de mudança (GG). 
A necessária cooperação dos estados e territórios era parcialmente obstada pela falta de mecanismos efetivos de coordenação. Os existentes - reuniões anuais dos premiers (autoridade máxima de um estado ou território; equivalente ao governador) e os ministerial councils (conselhos que discutem e propõem políticas para um determinado assunto; em geral composto pelo ministro titular da pasta, servidores da alta administração federal e estadual) - não produziam resultados pelo fato dos estados não se verem representados como parceiros (Carroll 2007). Ademais, a insatisfação dos estados com a distribuição de receitas fiscais era muito elevada.

Ainda no início dos anos 90, a economia australiana estava imersa em uma grave recessão. Há alguns anos a sociedade australiana tinha uma percepção de que estava perdendo terreno para as economias asiáticas e que se não se mobilizasse se tornaria irrelevante no cenário mundial (RP).

Hawke achava que as barreiras internas na Austrália eram maiores do que aquelas existentes entre os países da União Europeia. Ademais o combate à recessão necessitava da ativa presença dos estados para implementar um pacote de estímulos (RP).

O Primeiro Ministro propôs então a criação de uma agenda acordada com os estados. Os assuntos passariam a ser discutidos previamente em instâncias da administração nacional e estadual, colhendo subsídios para o processo decisório. Foi esse arranjo que deu lugar à criação do COAG, já sob a liderança de Keating, em 1992.

O COAG deveria desempenhar os seguintes papéis:

\begin{abstract}
"Aumentar a cooperação entre os estados visando o interesse nacional; perseguir reformas que consigam promover uma economia nacional eficiente e integrada e um único mercado nacional; dar continuidade à reforma estrutural do estado e à revisão das relações entre os governos; e considerar outros assuntos intergovernamentais ou relativos ao governo como um todo" (Griffith 2009).
\end{abstract}

Eram 1.700 regulamentos que precisavam ser revistos. Para que as reformas de fato ocorressem três outros mecanismos foram criados: a National Competition Policy (NCP), o National Competition Council (NCC) e o Regulation Impact Statement (RIS). A NCP criou as bases para o programa de reforma regulatória enquanto os outros dois serviram como instâncias de acompanhamento dos progressos nesse campo. Ambos tinham por objetivo avaliar a qualidade das regulamentações reformadas (NCC) e das novas regulamentações (RIS). 
Houve oposição por parte dos governos estaduais e dos sindicatos (RP) dado que a reforma regulatória também tinha impacto sobre o monopólio estatal na área da produção dos serviços de utilidade pública. De acordo com Carroll (2007), os avanços foram pequenos, até que o Tesouro da commonwealth, em 1995, passou a dar incentivos financeiros aos estados que progredissem na reforma regulatória e introduzissem a competição na oferta dos serviços de utilidade pública. Um dos primeiros resultados foi o "reconhecimento mútuo", pela qual a regulamentação de uma jurisdição é reconhecida por outra (RP).

Pelos estudos feitos pela Productivity Commission essa agenda foi muito bem sucedida, pois a produtividade na Austrália aumentou consideravelmente durante os anos 90 (GG):

\begin{abstract}
"As taxas médias de crescimento da produtividade variaram consideravelmente durante os sete ciclos que se sucederam, desde 1973-74. Entretanto, os melhores desempenhos são os do ciclo dos anos 1993-94a 1998-99, enquanto os piores são os do ciclo mais recente, de 2003-04 a 2007 -08. A taxa média de crescimento da Produtividade Multifatorial (MFP) da Austrália no período 1993-94 a 1998-99, de 2,1\%, foi bem superior àquelas de qualquer outro ciclo e mais de duas vezes maior do que a taxa média de longo prazo." (Productivity Commission 2009).
\end{abstract}

\title{
Howard e as mudanças no plano fiscal (1999-2007)
}

Howard, do partido conservador da Coalizão, venceu Keating, do Partido Trabalhista, precisamente pelas mudanças econômicas empreendidas, mas essas resultaram, alguns anos depois, em um significativo aumento da produtividade e da renda, como se viu acima, resultando em um verdadeiro milagre econômico (RP).

Em 1999, Howard criou o Goodsand Services Tax (GST), um imposto sobre bens e serviços que substituiu uma série de impostos federais e estaduais. O objetivo era o de simplificar a coleta de impostos. Ao mesmo tempo, determinou que as receitas do GST retornassem inteiramente para os estados. Igualmente ficou definido que essas receitas seriam alocadas livremente pelos estados, ao contrário dos Special Purpose Payments (SPP), transferências vinculadas feitas pelo governo da Commonwealth aos estados.

A proporção da distribuição das receitas obtidas com o GST passaria a ser indicada pela commonwelth Grants Commission e submetida ao Tesouro da commonwealth. 
O Tesouro formula um "quadro de referência" dentro do qual a Commonwealth Grants Commission deve especificar suas sugestões de como repartir o montante de GST entre os estados; isso significa que o Tesouro poderá determinar que certos montantes transferidos não sejam considerados pela comissão. Esse "quadro de referência" é divulgado e, portanto, de conhecimento público.

Por outro lado, como esses cálculos não são imediatos, pode ocorrer que o "desconto" de certas transferências (feitas a projetos, por exemplo) se dê após um ou mais anos após o fato ocorrido; isso pode criar problemas aos estados (que não se preparam para fazer as correções de perda de receita ao longo do tempo) e ao grupo político no poder, no momento do corte de receita.

Na mesma oportunidade foi criado um subcomitê ministerial para acompanhar a administração do GST e o Ministerial Council for Federal Financial Relations (Conselho Ministerial de Relações Financeiras da Federação). Esse conselho é presidido pelo titular do Tesouro Federal e reúne os tesoureiros dos estados, para pelo menos uma reunião anual e outras consultas e comunicações que os conselheiros entendam necessárias, no período entre as reuniões.

A despeito dessas mudanças, que passaram a dar maior flexibilidade aos estados e territórios, segundo alguns analistas (Griffith 2009), esses ainda não se sentiam confortáveis com essas decisões, pois tem pouco controle sobre o volume e a forma de distribuição da GST.

Os ataques terroristas ocorridos no início da década - a destruição das torres em Nova York e as bombas de Bali - impulsionaram Howard a convocar os estados para uma ação antiterrorista integrada, fortalecendo o COAG mais uma vez.

No início da década também, o governo da Commonwealth deu início à elaboração de planos de longo prazo e institucionalizou o Intergenerational Report, que faz projeções do desenvolvimento da Austrália nos próximos 40 anos. Já foram elaborados três planos até agora. Os planos focalizam o impacto do envelhecimento da população e suas consequências fiscais.

No início dos anos 2000 também estava se tornando evidente que os ganhos de produtividade, daí para frente deveriam se dar a partir de: um aumento da competitividade, da maior participação da força de trabalho e da melhoria do capital humano (GG).

Para fazer face aos desafios de médio e longo prazos, em 2006, o COAG formulou a National Reform Agenda (Agenda de Reforma Nacional), cujos focos eram precisamente:

- Competitividade (buscando aperfeiçoar áreas como planejamento, energia, transporte, infraestrutura e mudança climática);

- Participação da força de trabalho;

- Reforma regulatória (visando buscar as melhores práticas em uso no país ou fora e reduzindo a carga regulatória, especialmente em 35 áreas); 
- Capital humano (enfatizando as áreas da saúde, educação e treinamento e incentivos ao trabalho) (OECD2010).

Mais uma vez era impossível fortalecer a economia da Austrália e garantir seu desenvolvimento sem a cooperação dos estados. Agendas como aquelas referentes ao desenvolvimento do capital humano necessitam do engajamento da comunidade e é o estado a instância que tem melhores condições de estimular esse envolvimento (GG).

Em 2006 também foi criado o COAG Reform Council (CRC), uma entidade independente cujo propósito é o de monitorar e avaliar a implementação das agendas acordadas no âmbito do COAG.

\section{O Council for the Australian Federation (CAF)}

Ainda em 2006, os estados e territórios criaram o Council for the Australian Federation (CAF), reunindo somente os titulares dos estados e territórios, dandoIhes, ao mesmo tempo, apoio técnico. O CAF permite aos estados e territórios contrabalançar o poder do governo central.

Trata-se de um arranjo de cooperação horizontal que enseja a harmonização regulatória, aperfeiçoa o desenvolvimento de políticas e incentiva a inovação "ao facilitar a troca de idéias sobre 'o que funciona melhor' através do trabalho colaborativo entre os estados e territórios" (Griffith 2009). O CAF procura construir consensos entre os estados que são então levados ao COAG (OCDE 2010).

\section{Rudd e o Intergovernmental Agreement on Federal Financial}

\section{Relations: a contratualização entre entes federados (2007-2010)}

Kevin Rudd assumiu o governo da Commonwealth, ao final de 2007, em uma situação política atípica: todos os governos estaduais e dos territórios estavam sob o comando do Partido Trabalhista, assim como seu próprio governo. O governo Rudd também quis priorizar o COAG como organismo de alinhamento das políticas estaduais e nacionais. Ao longo de 2008, um Acordo Intergovernamental de Relações Financeiras Federais (Intergovernmental Agreement on Federal Financial Relations) foi construído entre o governo nacional e os subnacionais. 


\section{As transferências de GST}

O acordo prevê que os estados e territórios continuarão a receber as receitas do GST até 2011. As receitas referentes ao GST podem ser livremente utilizadas pelos estados; o rateio entre os estados se dá de acordo com o princípio da equalização horizontal.

A Commonwealth Grants Commission sugere, a cada ano, de acordo com orientações gerais recebidas do Tesouro, em que proporções as receitas de GST devem ser distribuídas entre os diferentes estados. As transferências de GST representam aproximadamente $50 \%$ das transferências recebidas pelos estados.

Mais recentemente, em abril de 2010, a Commonwealth e os estados - exceto o de Western Australia - concordaram em que o governo central passe a reter $30 \%$ da GST para serem investidos nas áreas da Saúde e dos hospitais.

\section{Os acordos nacionais}

Foram firmados seis Acordos Nacionais (National Agreements) nas áreas da saúde, escolas, desenvolvimento da força de trabalho e treinamento, serviços para pessoas com necessidades especiais, habitação e reformas concernentes à população aborígene. Cada Acordo Nacional contem:

- Objetivos;

- Resultados;

- Produtos;

- Indicadores e medidas de desempenho;

- Os papeis e responsabilidades de cada nível governamental.

Os seis Acordos Nacionais se sustentam em cinco Pagamentos para Propósitos Específicos (Specific Purpose Payments). Esses pagamentos são transferências feitas pelo governo nacional sem especificação de como os recursos devem ser gastos, contanto que os resultados previstos nos acordos sejam alcançados (COAG 2010).

A possibilidade de penalidades foi considerada, mas, nesse estágio, não foi incluída nos acordos. Esse arranjo constituiu um formidável avanço nas relações financeiras entre o governo nacional e os estados, pois reduziu o número de pagamentos de mais de 90 para cinco. Dentro do novo esquema, o Tesouro paga depois das atividades terem sido realizadas, de acordo com os resultados acordados.

O Tesouro passou a ser o responsável por definir o modelo de relatório de desempenho, verificando a consistência interna dos acordos, em termos da articulação entre objetivos, resultados, indicadores e informações (SV). O 
Tesouro também verifica a qualidade e a disponibilidade das informações, buscando alternativas para sua melhoria.

Ademais essas transferências são hoje feitas diretamente para os tesouros estaduais, que então as redistribuem para os diferentes setores. Todas as transferências passaram a ser feitas pelo Tesouro, substituindo o sistema mediante o qual as mesmas se davam do ministério setorial para as secretarias setoriais estaduais.

Essa nova forma de transferência permite aos estados um melhor gerenciamento de seus respectivos orçamentos e um conhecimento mais detalhado dos recursos que cada setor recebe. Essas flexibilidades objetivam promover a inovação e a melhoria dos métodos utilizados na prestação de serviços nos estados, ensejando o aumento da produtividade. Essas transferências são feitas sem requerer a detalhada prestação de contas que antes era solicitada aos estados e isenta os estados de um controle por processos.

No entender de alguns, a nova sistemática permite que a prestação de contas (accountability) se faça para a comunidade, que passa a exercer o papel de principal, em relação ao agente/estado (SV). Uma avaliação mais clara da nova sistemática só poderá ser feita dentro de quatro a cinco anos; contudo, se não houver melhora de desempenho por parte dos estados é possível a volta ao controle ex-ante (RP).As auditorias sobre os processos são feitas pelos órgãos de controle estaduais e não mais federais.

Os acordos nacionais têm cinco anos de duração, prazo após o qual serão revistos; provavelmente novos acordos serão então estabelecidos (AL).

Embora os resultados gerais a serem alcançados sejam os mesmos para todos os estados e territórios, há uma adequação, no nível mais detalhado, a cada estado e território, considerando a posição em que cada um está com respeito àquela área. Nesse sentido, os acordos acabam sendo bilaterais (entre o estado ou território e o governo central).

\section{Os acordos nacionais de parceria}

Além dos Acordos Nacionais, existem os Acordos Nacionais de Parceria (National Partnership Agreements) que são financiados pelo governo nacional, mas podem também receber a contribuição do estado ou território onde se desenvolverá o NPA. Atualmente são cerca de 50 e muitos foram orientados para o combate aos efeitos da crise financeira (SV).

Os Acordos Nacionais de Parceria podem assumir três formas:

- Pagamentos de projetos, para financiar projetos específicos;

- Pagamentos de facilitação, transferências orientadas à fase inicial de reformas ou melhoria do padrão de qualidade de algum serviço; e 
- Pagamentos de incentivos. Feitos quando são atingidas metas acordadas. (OCDE 2010).

Os pagamentos podem ser de um tipo ou a combinação de mais de um tipo. Se os estados não cumprem as metas desses acordos, os pagamentos podem ser suspensos. Quem delibera sobre os pagamentos são ministros do governo nacional.

Os pagamentos de incentivos servem como estímulo aos estados para que cumpram as metas acordadas; o pagamento é decidido pelo governo nacional, pode ser integral ou parcial, e considera as avaliações feitas pelo COAG Reform council.

Ainda não foram feitos pagamentos de incentivos, pois os acordos tem pouco tempo; mas em outras circunstâncias eles se mostraram bastante efetivos (COAG 2010). Os recursos para pagamentos de incentivos diminuíram, em relação ao que estava previsto, em função dos gastos realizados para contornar a crise financeira (RP).

\section{Alguns exemplos de Acordos Nacionais de Parceria}

Os Acordos Nacionais de Parceria (National Partnership Agreements) refletem a agenda de reformas do COAG e situam-se nas seguintes áreas:

- Reformas na área da saúde e da força de trabalho desse setor;

- Iniciativas referentes a "escolas mais conectadas";

- Habitação social;

- População sem-teto;

- Participação econômica da população indígena e assuntos correlatos; e

- Economia nacional sem fronteiras internas (reforma regulatória).

Esse último acordo, "Economia nacional sem fronteiras internas", prevê, por exemplo, para o primeiro ano, pagamentos de facilitação, e para os anos subsequentes, pagamentos de incentivos.

Essas reformas são dirigidas pelo Grupo de Trabalho para a Regulação do Setor Privado e da Competição do COAG, integrado por servidores públicos pertencentes à alta administração do governo federal e dos estados (Griffith 2009). Os pagamentos do governo central são feitos mediante desempenho. Quando não há desempenho, não há pagamento. Se as metas são alcançadas com atraso, os recursos são transferidos naquela oportunidade (AL).

Em fevereiro de 2009, diante da crise financeira global, a Austrália criou um "pacote de estímulos", através de um outro Acordo Nacional de Parceria: Nation Building and Jobs Plan (Plano de Construção Nacional e de Empregos). A 
Commonwealth e os estados concordaram com um plano para gastar 42 bilhões de dólares nos próximos quatro anos em 10 diferentes áreas:

- Construindo a revolução educacional;

- 20000 habitações sociais e de defesa;

- Lares energeticamente eficientes;

- Isenções de impostos de empresas em geral;

- Infraestrutura comunitária;

- Isenções de impostos para australianos que trabalham;

- Pagamento de bônus para famílias que dependem de um único salário;

- Pagamento de bônus para azares agrícolas;

- Pagamento de bônus para os que voltam à escola; e

- Pagamento de bônus para quem está estudando ou em treinamento.

O Plano de Construção Nacional e de Empregos tem sido muito bem sucedido, representando parte da explicação do crescimento econômico considerável e do baixo desemprego da Austrália, no presente momento.

\title{
Conselhos ministeriais
}

\begin{abstract}
"O Commonwealth-State Ministerial Councils Compendium (Compêndio das Comissões Ministeriais Intergovernamentais) define um conselho ministerial como uma reunião formal de ministros lo que equivale, no caso brasileiro, aos ministros de Estado, do Governo Federal, e os secretários estaduais das diferentes pastas) de mais de quatro entes federados, em geral envolvendo o governo federal, os estados e territórios, que se reúne regularmente. 0 papel dos conselhos ministeriais é o de facilitar consultas e cooperação, desenvolver políticas conjuntamente e tomar medidas na resolução de questões que surgem entre os entes da Federação Australiana" (COAG 2009).
\end{abstract}

Os conselhos ministeriais constituem espaços institucionais onde são iniciadas, desenvolvidas e monitoradas conjuntamente reformas de políticas e nas quais são tomadas medidas para a resolução de questões que porventura possam emergir entre os entes governamentais.

Especificamente, os conselhos ministeriais desenvolvem reformas de políticas a serem apreciadas pelo COAG e supervisionam a implementação de reformas de políticas acordadas pelo COAG (Griffith 2009).

Conselhos ministeriais já existem há bastante tempo na Austrália, mas o COAG tem buscado controlar seu número e sua forma de funcionamento. Existem atualmente 31 conselhos ministeriais mais três fóruns ministeriais. 
Os conselhos ministeriais se reportam ao COAG e recebem a contribuição de um conjunto de comissões especializadas, integradas por representantes eleitos ou servidores públicos dos diferentes entes.

Os objetivos, produtos, resultados e indicadores de desempenho dos Acordos Nacionais são elaborados pelos conselhos ministeriais e grupos de trabalho do COAG; são também os conselhos ministeriais que propõem projetos para serem financiados pelos Acordos de Parceria (SCRGSP 2009).

\section{Informação sobre o desempenho dos acordos}

Conforme previsto no Acordo Intergovernamental de Relações Financeiras Federais, o COAG Reform Council CRC (Conselho de Reforma do COAG) tem a responsabilidade de informar o Primeiro Ministro e os premiers sobre:

- O desempenho dos estados no alcance das metas previstas nos seis Acordos Nacionais e nos resultados previstos nos Acordos Nacionais de Parceria que sustentam objetivos implícitos nos Acordos Nacionais;

- O alcance de metas previstas em Acordos Nacionais de Parceria que dão direito a pagamento de incentivos;

- O progresso geral das reformas previstas na agenda do COAG.

O COAG Reform Council ( $\mathrm{CRC}$ ) é um conselho independente, cujo dirigente máximo é indicado pelo Primeiro Ministro; seu vice é indicado pelos estados; pelo menos um de seus membros representa os interesses regionais e rurais; os outros conselheiros podem ser acadêmicos e/ou representantes deda área privada. Todos tem larga experiência dentro ou fora do Governo e muito conhecimento, o que Ihes dá muita credibilidade (AL).

As despesas do CRC são custeadas pelo governo nacional (50\%) e pelos governos estaduais na proporção do tamanho de sua população. O CRC tem uma Secretaria Executiva e um corpo de 25 servidores, pertencentes ao governo nacional.

Os relatórios do CRC devem apresentar análises comparativas do desempenho, focalizando:

- Os indicadores de desempenho de alto nível dos Acordos Nacionais;

- Exemplos de boas práticas;

- Diferenças contextuais que possam explicar as diferenças de desempenho entre os estados; e

- A contribuição do governo federal e dos estados para o alcance dos objetivos do COAG e sua melhoria contínua.

Nem todos os Acordos Nacionais de Parceria estão sujeitos à avaliação do COAG Reform Council; isso só ocorre nos casos em que os Acordos Nacionais de 
Parceria contribuem para os Acordos Nacionais, ou quando estão previstos pagamentos de incentivos.

As avaliações são feitas por especialistas e o CRC pode também encomendar estudos específicos. Em média, o CRC produz 15 relatórios por ano. A cada ano também produz um relatório dos avanços da agenda de reformas do COAG, de forma agregada (AL).

Antes de tornar os relatórios públicos, o CRC consulta os estados, com um mês de antecedência. O CRC tem o direito de acatar ou não as contribuições advindas dos estados. O CRC não tem o papel de recomendar políticas, mas pode encomendar estudos especiais a consultores para fazer estudos comparativos e identificar boas práticas (AL).

O Steering Committee for the Review of Government Service Provision (Comitê Diretor para a Revisão dos Serviços Oferecidos pelo Governo), ou simplesmente, steering committee é encarregado de consolidar todas as informações referentes ao desempenho dos Acordos Nacionais.

Essas informações devem ser disponibilizadas em um período de três a seis meses após a realização da etapa prevista. O CRC publica seus relatórios três meses após a entrega dos dados pelo Steering Committe ou, eventualmente, outras agências às quais o CRC possa pedir informação.

É difícil, em geral, falsear as informações (gaming), pois elas são coletadas por meios muito robustos; ainda assim, os órgãos de auditoria identificaram algum falseamento em informações fornecidas diretamente por hospitais (AL).

A Productivity Commission (Comissão Supervisora da Produtividade), criada em 1998 a partir da fusão de outras organizações que a antecederam, tem por objetivo aconselhar o governo, a partir de estudos avaliativos da produtividade dos setores privado e público. A Productivity Commission deverá avaliar, a cada dois a três anos, o impacto econômico e os benefícios das ações referentes à Agenda do COAG.

O fluxograma abaixo retrata o processo de coleta, análise e interpretação de informações sobre o desempenho atingido pelos Acordos Nacionais: 
Figura 1. Performance reporting information flows.

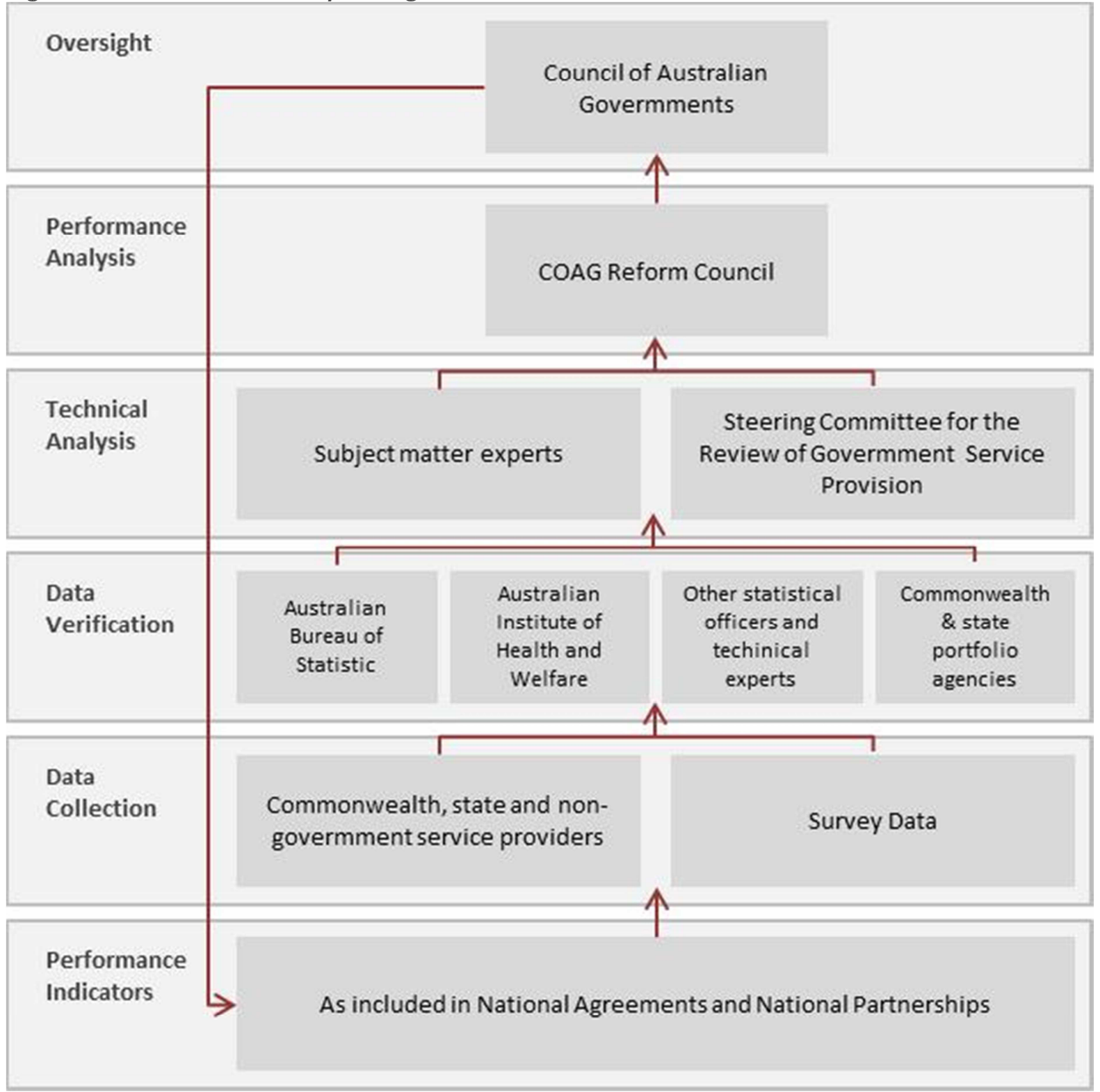

Fonte: adaptado de Budget Paper3 (2010-2011).

\section{As características da pactuação intergovernamental na Austrália}

Os parágrafos anteriores procuraram recuperar o processo de construção institucional do sistema de contratualização intergovernamental na Austrália. Suas características atualmente são as seguintes:

Orçamento global ou vinculado: como se viu acima, metade dos recursos transferidos aos estados corresponde a orçamentos não-vinculados (são os recursos provenientes da GST); a segunda metade se subdivide em dois grupos: as transferências feitas através dos Acordos Nacionais, nos quais o vínculo é 
setorial, os orçamentos são globais e a única restrição é que atinjam os resultados acordados; finalmente, um quarto dos valores transferidos é realizado através dos Acordos de Parcerias, estes sim vinculados a projetos específicos. Os estados consideram um grande progresso ter havido a diminuição do número de transferências vinculadas e lamentam certo retrocesso percebido nos últimos anos.

Processo de construção dos parâmetros: os parâmetros são acordados entre as partes e são adaptados à realidade de cada estado; em geral, procura-se um padrão básico para todos e a superação da situação atual de cada um.

Processo de revisão e atualização dos parâmetros: essa deverá se realizar quando os acordos forem revisados, ou seja, cinco anos após a assinatura dos mesmos.

Casos mais importantes e interessantes do ponto de vista setorial: segundo os entrevistados, os melhores acordos são aqueles que foram construídos sobre bases de dados sólidas. Foram destacados os da Educação e o referente aos Aborígenes. O primeiro pode se valer de informações de qualidade e com considerável periodicidade. O segundo foi construído sob a forte liderança da ministra da pasta e se baseou em inúmeros estudos, provenientes de diferentes setores e instituições, como a Productivity commission.

Processos de responsabilização e prestação de contas: há instâncias governamentais às quais se prestam contas - o COAG principalmente - e há o público, dado que esses resultados são disponíveis pela internet.

Quando os partidos são diferentes a política interfere? Pode haver alguma interferência política na distribuição dos recursos da GST, se o Governo, através do Tesouro, determinar à Comonwealth Grants commission (CGC) que exclua algum investimento, ou transferência já realizada, do montante a ser transferido. Mas, os termos de referência dados à CGC são públicos e podem ser repudiados pelos agentes políticos ou cidadãos. Pode também haver resistência política de algum estado não afinado com o governo da Commonwealth: é o caso de West Australia que não aceitou a retenção de 30\% da GST para serem investidos em Saúde e hospitais.

Casos de gaming (falsear as informações prestadas): são raros, pois as informações utilizadas são colhidas por organizações independentes. As informações também passam por testes estatísticos de consistência, realizados por instituições especializadas.

Casos de mau desempenho: punir retirando recursos ou renovar a aposta em que bases? A opção até o momento não é a de punir com falta de pagamento os estados com mau desempenho; a punição hoje é a publicidade dos (bons e maus) resultados; a exceção fica com os pagamentos de incentivos, que somente 
são pagos quando se dá a superação de metas; mas esses pagamentos estão temporariamente suspensos pela falta de fundos.

Papel do legislativo e dos órgãos de controle: Tendo em vista que o sistema é parlamentarista, a divisão entre o legislativo e o executivo não se dá da mesma maneira como em sistemas presidencialistas. Dentro do Parlamento, a oposição tem acesso à informação e pode questionar os acordos. No entanto, nenhum entrevistado se referiu a maiores entraves causados pela oposição. Os órgãos de controle se atem a auditar a esfera de sua competência. Também aqui nenhum entrevistado se referiu a tensões com os mesmos.

\section{Avaliações do "federalismo contratual" a partir da visão dos estados}

Os estados com frequência entendem o COAG como uma construção institucional que representa um avanço para a cooperação federativa.

Em seu estudo, Griffith (2009) aponta para dois casos distintos de cooperação, no âmbito do COAG: um se refere à gestão de bacias, o outro à harmonização da legislação que rege os profissionais de saúde no país. As estratégias administrativas nos dois casos são distintas, levando, no primeiro caso, a uma supremacia do governo federal sobre os estaduais; no segundo caso, a cooperação entre os entes é mais igualitária.

\section{As críticas à centralização}

Frequentemente, no entanto, são apontados casos de interferência indevida do governo federal em áreas caracteristicamente estaduais. Existe uma tensão inerente na federação.

Os Acordos de Parceria estão se tornando novamente muito detalhados, de certa maneira um retrocesso para a reforma de 2007, segundo alguns. Os níveis mais baixos da burocracia tendem a impor restrições. Também é possível que estejam respondendo a alguns lobbies. (AT)

Há quem veja o COAG como um instrumento de submissão dos estados ao governo central: a agenda é definida pelo governo central e o Primeiro Ministro preside o organismo (MK \& LD).

Assuntos como imigração e mudanças climáticas não sobem para a agenda, mesmo que sejam do interesse dos estados. Os incentivos são menores do que os esperados; maior autonomia seria um ótimo incentivo. Há quem entenda que 
existe uma pressão por parte da Commonwealth para assinar os acordos. O governo central acaba por querer impor uma padronização, embora os estados sejam diferentes (LD). As economias estaduais são distintas e devem ser tratadas de modo diferenciado (MK), do ponto-de-vista de representantes dos estados.

A assimetria entre os estados e a Commonwealth também se revela no fato de que somente os resultados dos estados tem publicidade; a mesma transparência não está presente nas atividades do governo central.

O Governo do Estado de New South Wales submeterá proximamente, ao Comitê da Reforma da Federação Australiana, do Senado, suas contribuições. Entre elas destaca o desequilíbrio fiscal vertical que persiste na federação australiana; questiona igualmente as recomendações de equilíbrio horizontal, feitas pela commonwealth Grants Commission.

Com referência ao COAG irá recomendar um Acordo Intergovernamental que discipline sua operação pois:

"freqüentemente as negociações não são ideais dado que: i) não permitem consultas adequadas; ii) não reconhecem diferentes modelos de prestação de serviços existentes na Austrália; e iii) ocasionalmente o financiamento é usado para forçar um acordo." (NSW Government:8).

O documento também aponta que:

“... os Acordos Intergovernamentais deveriam ser negociados $e$ elaborados de maneira a reconhecer os estados como governos soberanos sofisticados, que por sua iniciativa se dispóem a promover a colaboração e a cumprir acordos em prazos estabelecidos." (NSW Government:9).

Sugerindo igualmente não caber a imposição de exigências legais nesses acordos.

Autores como Griffith e Towmey enxergam que os parlamentos estaduais tem visto seu poder diminuído dado que, apesar de poderem referendar e/ou emendar os acordos, quando esses são submetidos os detalhes já foram definidos.

Em sua contribuição para o mesmo Select Committee on the Reform of the Australian Federation (Comitê da Reforma da Federação Australiana, do Senado) 
Twomey (2010) sugere que um organismo independente redefina, e de modo mais claro, as atribuições de cada nível de governo, pois hoje as responsabilidades estão superpostas, dificultando uma avaliação mais correta por parte dos cidadãos. A mesma autora sugere uma redistribuição dos recursos para cada nível governamental para permitir que cada um tenha os fundos necessários para o desempenho de suas atribuições. Finalmente, também propõe uma emenda constitucional que permita a cooperação intergovernamental, a criação de acordos entre os entes, sua alteração e/ou rescisão.

\section{O papel do CAF}

O CAF é considerado como uma boa iniciativa, segundo alguns, ainda que não muito efetiva, pois, afinal, os estados competem, entre si, pelos mesmos recursos (AL). Por alguns é considerado um espaço de encontro útil, mas sua eficácia também depende de quem o preside. Sua presidência é rotativa: quando um estado forte o lidera há mais probabilidade das iniciativas serem bemsucedidas (LD).

O CAF tem boas ideias; está encomendando pesquisas importantes, mas ainda não teve impacto (GG). Aos olhos de alguns representantes estaduais, no entanto, o CAF (MK) não tem poder, não pode tomar decisões de caráter nacional; pode tentar construir alinhamento entre os estados (GG).

\section{Avaliação geral feita pelos entrevistados}

O atual experimento de contratualização entre o governo da Commonwealth e os estados poderá trazer benefícios. De certa maneira, ele vem para superar a baixa capacidade de implementação dos estados. A capacidade das burocracias estaduais é bastante desigual e o gap entre essas e a burocracia do governo central também é grande (GG). A curva de aprendizado é semelhante em todos os setores e organizações (SV).

O COAG Reform Council, no entender de alguns entrevistados (AT) é a melhor contribuição dos novos arranjos para a melhoria dos serviços públicos, pois não retira recursos, mas torna os resultados públicos. (AT)

\section{O papel e a importância política dos estados}

Frequentemente se ouve falar em extinguir os estados; poderiam ser substituídos por governos regionais segundo alguns e segundo outros o governo local deveria 
ser fortalecido $(\mathrm{JH})$. Com frequência os cidadãos australianos procuram seus representantes nacionais para resolver questões locais (JS).

Os eleitores não distinguem claramente quais são as atribuições dos estados e da Commonwealth e frequentemente se voltam para os políticos nacionais para resolver questões locais, pois aí estão os recursos. (AT) Os políticos nacionais também se valem de questões que são da competência dos estados para fazer anúncios, para assim se manter em evidência (LD).

A escolha de representantes nacionais é feita por um comitê partidário distinto dos comitês que escolhem candidatos a postos eletivos estaduais. Em parte isso explica o fato de que praticamente não existe uma ascensão de um posto estadual para um posto federal. As carreiras políticas não são construídas dessa maneira (JS).

Políticos que chegam a ocupar um posto elevado no governo central construíram provavelmente suas carreiras junto a outros políticos, assessorando-os nos ministérios; no caso do Partido Trabalhista, a ascensão a um elevado posto político no governo nacional também pode ser facilitada por uma carreira dentro de um sindicato. O alinhamento dos políticos é sempre partidário, nunca se faz por interesses regionais, mesmo no Senado.

\section{A relação dos estados entre si e o aprendizado mútuo}

O intercâmbio entre os estados não é grande, portanto não aprendem muito uns com os outros (AL). Mas o sistema permitirá esse processo. Faz parte dos objetivos do CRC se tornar um laboratório de políticas: "precisamos ainda aprender como extrair lições do feedback que nos é dado", segundo Geoff Gallop.

Do ponto de vista de alguns entrevistados, os conselhos ministeriais e os grupos de trabalho do COAG são mecanismos mais efetivos de aprendizado. Há quem considere que o COAG Reform Council atue em duplicidade com a Productivity Commission e que as comparações entre os estados não são possíveis, devido à singularidade de cada um (LD).

Os novos arranjos não estão tendo ainda os resultados esperados. A mudança de cultura necessária é grande e leva tempo. A busca de resultados, ao invés do controle por produtos é uma mudança profunda à qual os ministérios setoriais e as burocracias estaduais ainda não se ajustaram.

Um ponto de estrangulamento é a informação: sua qualidade nem sempre é boa e/ou nem sempre está disponível no tempo necessário (GG). Há quem questione também a qualidade dos indicadores e dos benchmarks (LD). Os acordos não têm a mesma consistência e qualidade (AL). 
Frequentemente as informações disponíveis não permitem uma avaliação criteriosa dos resultados que devem ser alcançados. Às vezes, a periodicidade de coleta dos dados impede acompanhar o progresso de determinado indicador. A comparabilidade também, por vezes, é prejudicada: por exemplo, os estados enfrentam a questão do acesso aos serviços, por portadores de necessidades especiais, de maneiras muito diferente; fica então difícil criar informações comparativas (LD).

\section{Os novos arranjos}

"Os estados tem que se reformar, para se tornarem mais efetivos. Tem que melhorar seu desempenho e se engajar com a comunidade, do contrário não alcançaremos resultados nas áreas sociais. Muitos dos objetivos perseguidos nessas áreas dependem de mudanças de comportamento dos cidadãos e para que isso ocorra, eles têm que estar envolvidos. (...) O engajamento dos cidadãos é a grande questão do governo contemporâneo." (GG).

Ademais, é fundamental obter o apoio político dos cidadãos para essas reformas, segundo o mesmo entrevistado; somente dessa maneira será possível superar eventuais obstáculos que forças políticas contrárias interpõem (como os sindicatos, por exemplo) (GG).

A despeito do desequilíbrio entre os estados e o governo nacional, o COAG representa um avanço; é melhor tê-lo do que não tê-lo (MK); o enfrentamento da crise financeira, por exemplo, pela ação conjunta do governo central, estados e territórios, foi, sem dúvida, um caso de sucesso (LD); a mesma visão é compartilhada por setores regulados pelo governo nacional e pelos estados.

\section{Conclusões: a eficácia do sistema e alguns de seus entraves}

O experimento da contratualização intergovernamental é ainda muito recente na Austrália para que se possa fazer dele uma avaliação. Como concluiu Pollitt, as reformas de gestão levam muitos anos para se consolidar (Pollitt 2010).

O experimento ocorre dentro de uma história de muitas tensões entre o governo central, de um lado, os estados e territórios do outro, o que é bastante frequente nas federações. Há mudanças culturais importantes que devem se realizar, para que tenha êxito, tanto na burocracia nacional, quanto nas estaduais. Parecem pouco claros os limites de atuação dos agentes políticos atuando do lado dos estados e do governo nacional.

O processo ocorre dentro de uma história de construção institucional que não pode ser desprezada, e que Ihe dá bastante substância a despeito de ser recente. 


\section{Lições para o Brasil?}

Austrália e Brasil são países com muitos pontos de semelhança, outros tantos de diferença.

Em comum tem o tamanho do território - aproximadamente o mesmo; são países relativamente jovens, se comparados com as metrópoles das quais foram colônias. Suas economias estão se tornando mais semelhantes, dado que ambos são grandes exportadores mundiais de commodities, às vezes dos mesmos produtos. Do ponto-de-vista institucional se assemelham por serem federações. Ambas as constituições definem mais de um ente como responsável pelos serviços e setores.

Por outro lado, a população brasileira é quase dez vezes maior que a da Austrália. Embora a diversidade entre regiões possa ser semelhante, a quantidade de população introduz uma complexidade maior, no campo político, no caso brasileiro.

Embora a sociedade australiana seja heterogênea do ponto-de-vista cultural, as desigualdades sociais são muito menores: o país detém o segundo melhor IDH do mundo, segundo os dados recentes das Nações Unidas.

As tradições institucionais são muito diferentes: anglo-saxã, no caso australiano e latina, no caso brasileiro. Os sistemas de governo, parlamentarista, no caso australiano, e presidencialista, no caso brasileiro, dão diferentes incentivos à dinâmica federativa: no Brasil o poder dos estados, político e financeiro é bastante maior.

Embora autores como Abrucio (2010) indiquem que o papel dos estados se encontre, nesse momento, indeterminado, o período de redemocratização e a Constituição de 1988 fortaleceram estados e municípios. O Senado, enquanto instituição, representa, com frequência, a defesa dos interesses dos estados, no Brasil, o que aparentemente não é o caso da Austrália (AT).

A despeito das diferenças, o experimento do COAG pode representar uma inspiração para inovações institucionais no Brasil:

- Construir agendas explícitas e comuns entre os estados, contratualizando resultados claros, a partir e com os incentivos da União, pode mover muitas políticas públicas;

- Criar oportunidades de aprendizado mútuo igualmente, e nesse sentido os conselhos de secretários estaduais como o CONFAZ, CONASS, CONSED, CONSEPLAN E CONSAD representam já iniciativas bem-sucedidas (Hiro 2008);

- Investir em mecanismos de monitoramento e avaliação, e seu pressuposto, a informação, também são muito importantes, como 
demonstram os exemplos já existentes no país, como o IDEB. Nesse sentido o exemplo australiano é muito interessante:

- O COAG Reform Council tem uma governança ampla, que reforça grandemente sua legitimidade;

- A publicidade dos resultados introduz a possibilidade do controle social;

- O acompanhamento das metas pela Productivity Commission fortalece o monitoramento;

- O Tesouro assume o papel de controlar a qualidade dos contratos;

- As políticas públicas vão sendo corrigidas a partir de evidências;

- O acompanhamento mais acurado do volume de transferências para cada estado e setor e a busca de uma equalização fiscal horizontal parecem mecanismos que também poderiam ser de interesse para o Brasil.

- Por outro lado, o CAF (Conselho de Governadores) representa uma instância de agregação interessante, a exemplo do caso estadunidense;

- Finalmente, o COAG representa também uma instância de construção de políticas intersetoriais para o governo central e estados;

- A despeito das tensões interiores ao sistema e os prováveis desvios, existe um propósito permanente de planejar o país no curto, médio e longo prazos, de colocar metas e prevenir perdas, como atestam a instituição do Intergenerational Report. O acompanhamento da produtividade, como mostrado acima, orienta as políticas macro e microeconômicas e essas tem tido êxito.

A contratualização intergovernamental de resultados na Austrália, ainda que percebida como problemática por alguns dos entrevistados, é também vista como um avanço em relação à sua situação anterior e pode representar, no caso brasileiro, frutífera inspiração.

\section{Referências}

Abrucio F. Federalismo e políticas públicas: o impacto das relações governamentais no Brasil. In: Medeiros PC, Levy E (Orgs.). Construindo uma nova gestão pública. Escola de Governo do Rio Grande do Norte. Rio Grande do Norte: SEARH, 2010.

Bennett S. The politics of the Australian federal system. Research Brief 4, 200607. Parliament of Australia - Department of Parliamentary Services, 2006.

Carroll P. Federalism and intergovernmental relations: COAG, the NCP, and RIS. 2007. 
Charbit C, Michalun M. Mind the gaps: managing mutual dependence in relations among levels of government. OECD Working Papers on Public Governance 14. OECD Publishing, 2009.

Council of Australian Governments (COAG). Commonwealth-State Ministerial Councils Compendium. Commonwealth Government, Department of the Prime Minister and Cabinet, 2009.

Council of Australian Governments (COAG). Meeting the challenge: COAG's Reform Agenda. Publicado pelo Primeiro Ministro e Gabinete do Governo da Austrália, Junho 2010 b.

Council of Australian Governments (COAG). The Council of Australian Governments and the Coordination of Commonwealth and State Funding and Service Delivery and how it is enforced. Apresentação feita pelo Sr. Ron Perry. COAG Unit, Dept. of the Prime Minister and Cabinet, August 2010a.

Griffith G. Managerial federalism - COAG and the states. NSW Parliamentary Library Research Service Briefing Paper 10/09, 2009.

NSW Government. New South Government Submission to the Select Committee on the Reform of the Australian Federation. Mimeo, 2010.

Organization for Economic Co-operation and Development (OECD). OECD reviews of regulatory reform, Australia 2010: towards a seamless national economy. Paris: OECD, 2010.

Productivity Commission. Enhancing Australia's productivity growth. Annual Report 2007-2008. 2008. Disponivel na internet em: http://www.pc.gov.au/_data/assets/pdf_file/0006/83868/chapter01.pdf [Acesso em out. 2011].

Productivity Commission. Recent developments in Australia's Productivity. Annual Report 2009-2010. 2009. Disponivel na internet em: http://www.pc.gov.au/_data/assets/pdf_file/0018/103356/04-appendixa.pdf [Acesso em out. 2011].

Sano H. Articulação horizontal no federalismo brasileiro: os Conselhos de Secretários Estaduais. Tese (Doutorado) - Escola de Administração de Empresas (FGV-SP), 2008.

Steering Committee for the Review of Government Service Provision (SCRGSP). National Agreement performance information 2008-09: National Indigenous Reform Agreement. Canberra: Productivity Commission, 2009.

Twomwy A. Submission to the Select Committee on the Reform of the Australian Federation. University of Sydney, 29 August 2010. 


\section{Anexo}

\section{Entrevistas}

\section{Sr. Ron Perry (RP)}

Presidente da COAG Unit (departamento de apoio a atividades do council of Australian Governments)

Sra. Sue Vroombout (SV)

Gerente geral da Divisão das Relações entre Governo Federal e Estados do Tesouro

Sr. John Spasojevic (JS)

Presidente da secretaria da Commonwealth Grants Commission

Sra. Megan Kirchner (MK)

Diretora Assistente - Prioridades do COAG

National Reform Branch - Department of Premier and Cabinet

Governo do Estado de Victoria

Prof. Dr. John Halligan (JH)

Professor da Faculdade de Administração de Empresas e Governo da Universidade de Canberra - Centre for Research of the Public Sector

Sra. Mary Ann O'Loughlin (AL)

Presidente da Secretaria que apoia o Conselho de Reforma do COAG, responsável pelas avaliações e cumprimento dos Acordos Intergovernamentais

Sra. Liz Develin (LD)

Diretor Geral Adjunto - National Reform Unit

Policy and Strategy Division

Secretaria do Primeiro Ministro e do Gabinete

Governo do Estado de New South Wales

Prof. Geoff Gallop (GG)

Graduate School of Government University of Sydney

Parlamentar na Assembléia Legislativa do Estado de Western Australia (19862006)

Ministro (1990-1993)

Líder da oposição (1996-2001)

Premier (chefe do executivo) do Governo do Estado de Western Australia (20012006)

Conselheiro do COAG Reform Council

Dr. Anne Twomey (AT)

Professora Associada da Faculty of Law da University of Sydney 